\title{
Electrical characterization of si nanowire GAA-TFET based on dimensions downscaling
}

\author{
Firas Natheer Abdul-Kadir', Yasir Hashim², Mohammed Nazmus Shakib ${ }^{3}$, Faris Hassan Taha ${ }^{4}$ \\ ${ }^{1,4}$ Department of Electrical Engineering, College of Engineering, University of Mosul, Iraq \\ ${ }^{2}$ Department of Computer Engineering, Faculty of Engineering, Tishk International University, Iraq \\ ${ }^{3}$ Faculty of Electrical and Electronics Engineering Technology, Universiti Malaysia Pahang, Malaysia
}

\begin{tabular}{l} 
Article Info \\
\hline Article history: \\
Received Apr 30, 2020 \\
Revised Aug 13, 2020 \\
Accepted Sep 8, 2020 \\
\hline
\end{tabular}

\section{Keywords:}

Downscaling

GAA

Nanowire

Sub-threshold swing

TFET

\begin{abstract}
This research paper explains the effect of the dimensions of Gate-all-around $\mathrm{Si}$ nanowire tunneling field effect transistor (GAA Si-NW TFET) on ON/OFF current ratio, drain induces barrier lowering (DIBL), sub-threshold swing (SS), and threshold voltage $\left(\mathrm{V}_{\mathrm{T}}\right)$. These parameters are critical factors of the characteristics of tunnel field effect transistors. The Silvaco TCAD has been used to study the electrical characteristics of Si-NW TFET. Output (gate voltage-drain current) characteristics with channel dimensions were simulated. Results show that $50 \mathrm{~nm}$ long nanowires with $9 \mathrm{~nm}-18 \mathrm{~nm}$ diameter and $3 \mathrm{~nm}$ oxide thickness tend to have the best nanowire tunnel field effect transistor (Si-NW TFET) characteristics.
\end{abstract}

This is an open access article under the CC BY-SA license.

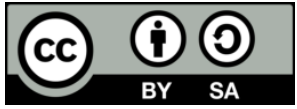

\section{Corresponding Author:}

Yasir Hashim,

Department of Computer Engineering,

Tishk International University (TIU),

Kurdistan-Erbil, Iraq.

Email: yasir.hashim@tiu.edu.iq

\section{INTRODUCTION}

The tunnel field-effect transistor (TFET) is a semiconductors device used to a promising candidate at low power applications in nanometer scales mostly because the conventional metal-oxide-semiconductor field effect transistor (MOSFET) approached the physical and thermal limits. However, the essential physical limitation of MOSFET that is to scale them at the submicron region is the pursuing short channel effects (SCEs) [1]. The silicon nanowire transistor is also used as a candidate device which has the excellent gate controlled and highly influenced electrical behavior to overcome the problems caused by short channel effects [2-5]. In the last decade, the rapid development in shrinking of semiconductors device led to the short channel effects as very harsh problem such as increasing drain induced barrier lowering (DIBL), and many research have been done in the last decade to find the substitutive device structure for striving improvements. Subsequently device structures such as double-gate (DG), surrounding-gate (SG), gate all around (GAA) and carbon nano tube (CNT) FinFETs and graphene-nano-ribbon (GNR) transistors have been incited for resolving the scaling matter of bulk transistors [6-11]. Gate all around-silicon nano wire tunneling FET (GAA-SiNWTFET) has most optimized gate structure than the FinFETs. The key performance for a transistor is the drain current $\left(\mathrm{I}_{\mathrm{d}}\right)$, drain induced barrier lowering (DIBL), threshold voltage $\left(\mathrm{V}_{\mathrm{T}}\right)$, sub-threshold slop (SS) and faster switching performance $\left(I_{\mathrm{ON}} / I_{\mathrm{OFF}}\right)$ which is related to the sub-threshold slop when the transistor operate at low voltage [12]. 


$$
\mathrm{SS} \cong\left(1+\frac{C_{d}}{C_{o x}} \ln \frac{K T}{q}\right)
$$

Where $C_{d}$ and $C_{o x}$ are the drain and oxide capacitance, respectively with:

$$
\ln \frac{K T}{q}=60 \mathrm{mV} / \mathrm{dec}
$$

The sub-threshold slop (SS) is the voltage applied on the gate to change the drain current by decade [13]. To obtaining a low sub-threshold slop (SS $<60 \mathrm{mV} / \mathrm{dec}$ ) and high switching performance $\left(I_{\mathrm{ON}} / I_{\mathrm{OFF}}>10^{5}\right)[14]$, the quantum mechanism in tunneling TFETs has been introduced as a substitution carrier injection mechanism in MOSFETs which suffers from thermal limitation [15-17]. Other advantages of the TFETs are to reduce leakage current, and to provide higher current than the MOSFET, better electrostatic control, prevention of the short channel effects and suitable to fabricate with CMOS processing techniques [18-22]. Therefore the TFETs have been gaining popularity over MOSFETs in the technology nodes [23]. Several excellent article and overview have been done in the last few years ago, which summarize the TFET modern on specific TFET topic [24]. According to aforementioned results that are about characterization and features for TFET, this paper is proposed.Therefore the importance of the work lies in what it shows from investigated characterization for electrical parameters which can be critical factor of TFET.

\section{RESEARCH METHOD}

The GAA NW Si-TFET is a P-I-N structure with an intrinsic semiconductor part (I) between heavily doped source $\left(\mathrm{p}^{+}\right)$and the drain $\left(\mathrm{n}^{+}\right)$. By using band-to-band tunneling FET mechanism, gate all around controls the tunneling between the channel and (source and drain) regions as showed in Figure 1 [25] Figure 2 shows a cross-sectional area of the device. The silicon channel radius is $(\mathrm{R})$ for the gate length $(\mathrm{L})$ which has doping concentration with $10^{16}$ per $\mathrm{cm}^{-3}, \mathrm{SiO}_{2}$ has been used as a gate oxide dielectric and the constant doping profile has been selected of $10^{20}$ per $\mathrm{cm}^{-3}$ for the both source and drain region. The tunneling process is transfer electron or hole through the junction, this process causes pairs of electrons and holes, hence the transfer rates of electrons and holes are opposite and equal [26]. We used in this work non local band to band tunneling model to vestige the tunneling generation rate across a tunneling length and incorporates the change in the electric field along the tunneling length. This model is more accurate for reverse biased tunneling junction with high doping and conservation sub- threshold slop up to $60 \mathrm{mV} / \mathrm{dec}$.
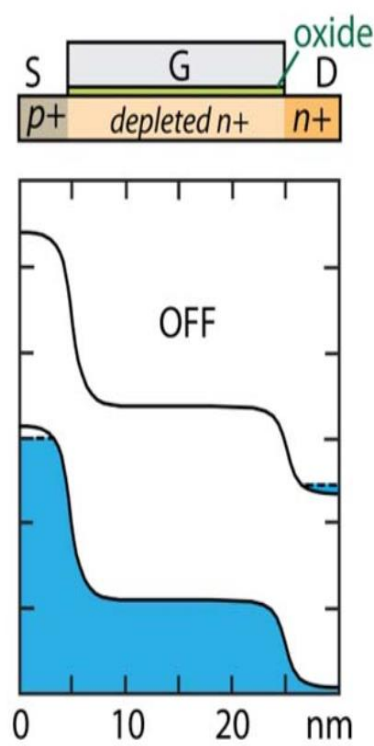

(a)
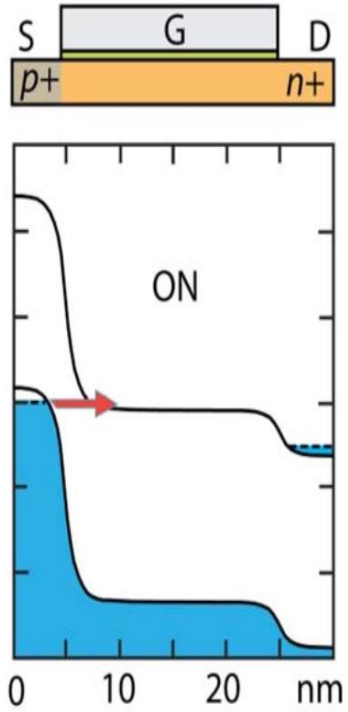

(b)

Figure 1. Energy band for a TFET a normally off device. (a) the gate fully depletes the channel,

(b) a positive gate voltage turns the channel on [23]

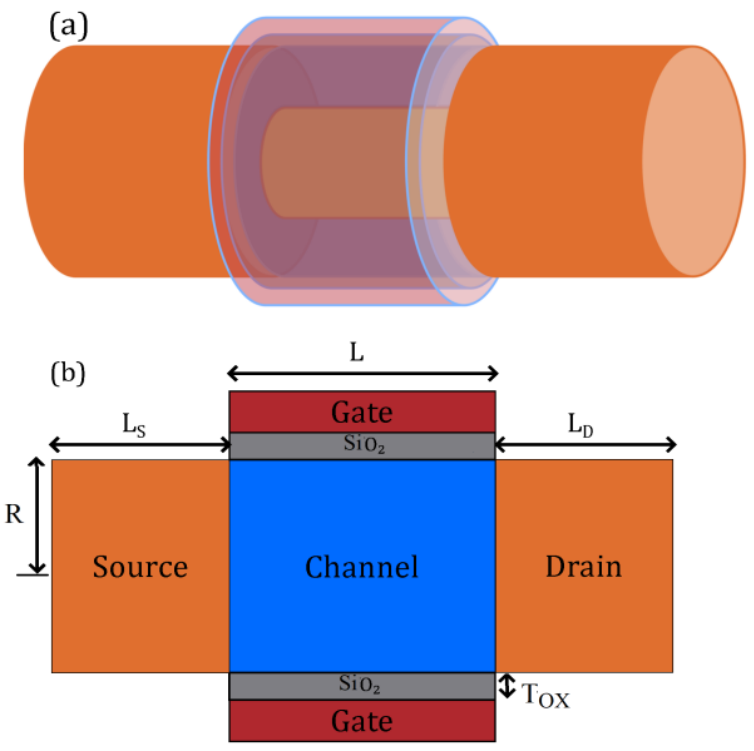

Figure 2. The schematic 3D structure, and (b) the overall dimension of GAA FET 
The device has been structured and simulated by using Silvaco TCAD [27] in specified scaling down dimensions within underlying physics with tunneling phenomena proposed by Kane [28]. The designed TFET in this paper, simulate with various dimensions for channel radius (R), channel length (L) and gate oxide thickness ( $\left.\mathrm{T}_{\mathrm{OX}}\right)$ to study the electrical characterization and analysis importance parameters effects on the device such as DIBL, SS, $\mathrm{G}_{\mathrm{m}}, \mathrm{V}_{\mathrm{T}}$ and ON/OFF current ratio. The dimensions profile has been selected to be $(25,18,9,5) \mathrm{nm}$ for channel radius, $(200,100,50,25) \mathrm{nm}$ for channel length and $(4,3,2,1) \mathrm{nm}$ for gate oxide thickness. The software can generate useful characteristic GAA TFET curves for researchers, especially to fully explain the underlying physics of TFET.

This simulation tool is utilized to investigate the characteristics of the Si-GAA TFET based on various channel's parameters. The output characteristic curves of the transistor under different conditions and with different parameters are considered. The effects of variable channel dimensions, namely; channel length, width and oxide thickness in addition to scaling factor of the TFET, are determined based on the I-V characteristics that derived from the simulation. In this paper, the $I_{d}-V_{g}$ characteristics of transistor at the temperature of $300 \mathrm{~K}$ are simulated and evaluated with the simulation parameters for channel lengths, channel diameters, and channel oxide thicknesses have been listed in Table 1.

Table 1. Simulation parameters

\begin{tabular}{|c|c|c|c|c|}
\hline \multirow{2}{*}{$\begin{array}{r}\text { Simulation type } \\
\text { Channel length effect }\end{array}$} & \multicolumn{2}{|c|}{ Variable Parameters } & \multicolumn{2}{|c|}{ Constant Parameters } \\
\hline & Channel length (L) & $(25,50,100$, and 200) $\mathrm{nm}$ & Channel radius $(\mathrm{R})$ & (5) $\mathrm{nm}$ \\
\hline & & & Oxide thickness $\left(\mathrm{T}_{\mathrm{OX}}\right)$ & (1) $\mathrm{nm}$ \\
\hline & & & Channel Doping (P) & $10^{16} \mathrm{~cm}^{-3}$ \\
\hline & & & Drain Doping $\left(\mathrm{P}^{+}\right)$ & $10^{20} \mathrm{~cm}^{-3}$ \\
\hline & & & Source Doping $\left(\mathrm{N}^{+}\right)$ & $10^{20} \mathrm{~cm}^{-3}$ \\
\hline & & & Drain length & $80 \mathrm{~nm}$ \\
\hline & & & Source length & $80 \mathrm{~nm}$ \\
\hline Channel radius effect & Channel radius $(\mathrm{R})$ & $(5,9,18$, and 25$) \mathrm{nm}$ & Channel length (L) & (200) $\mathrm{nm}$ \\
\hline & & & Oxide thickness $\left(\mathrm{T}_{\mathrm{OX}}\right)$ & (1) $\mathrm{nm}$ \\
\hline & & & Channel Doping (P) & $10^{16} \mathrm{~cm}^{-3}$ \\
\hline & & & Drain Doping $\left(\mathrm{P}^{+}\right)$ & $10^{20} \mathrm{~cm}^{-3}$ \\
\hline & & & Source Doping $\left(\mathrm{N}^{+}\right)$ & $10^{20} \mathrm{~cm}^{-3}$ \\
\hline & & & Drain length & $80 \mathrm{~nm}$ \\
\hline & & & Source length & $80 \mathrm{~nm}$ \\
\hline Channel Oxide thickness & Oxide thickness $\left(\mathrm{T}_{\mathrm{OX}}\right)$ & $(1,2,3$, and 4$) \mathrm{nm}$ & Channel length (L) & (200) $\mathrm{nm}$ \\
\hline effect & & & Channel radius $(\mathrm{R})$ & (5) $\mathrm{nm}$ \\
\hline & & & Channel Doping (P) & $10^{16} \mathrm{~cm}^{-3}$ \\
\hline & & & Drain Doping $\left(\mathrm{P}^{+}\right)$ & $10^{20} \mathrm{~cm}^{-3}$ \\
\hline & & & Source Doping $\left(\mathrm{N}^{+}\right)$ & $10^{20} \mathrm{~cm}^{-3}$ \\
\hline & & & Drain length & $80 \mathrm{~nm}$ \\
\hline & & & Source length & $80 \mathrm{~nm}$ \\
\hline
\end{tabular}

Three simulation steps were conducted to evaluate the dimensions dependent performance of TFET in terms of the considered metrics. In the first step, channel length has been varied, whereas other channel dimensions ( $\mathrm{R}$ and $\mathrm{T}_{\mathrm{ox}}$ ) were kept with constant values. In the second step, the effect of changing channel diameter has been investigated with both channel length and oxide thickness of channel was kept constant. In the final step, oxide thickness was varied and length and radius of channel were fixed.

\section{RESULTS AND DISCUSSIONS}

In this section, the results of dimensional effect on the electrical characteristics presented and discussed. Downscaling of length of channel (L), radios of nanowire of channel (R), and oxide thickness ( $\left.\mathrm{T}_{\mathrm{OX}}\right)$ and its effect on the $\mathrm{I}_{\mathrm{ON}} / \mathrm{I}_{\mathrm{OFF}}$ ratio, sub-threshuld swing (SS), drain indused barrier lowering (DIBL), treshuld voltage $\left(\mathrm{V}_{\mathrm{T}}\right)$, and transconductance $\left(\mathrm{G}_{\mathrm{m}}\right)$ of channel have been studied.

\subsection{Downscaling channel length}

The result of the effect of scaling down of channel length (L) on the electrical characteristics of GAA NW-TFET has been investigated, the channel length $\mathrm{L}$ has been scaled down from $200 \mathrm{~nm}$ to $25 \mathrm{~nm}$, whereas oxide thickness and radius were kept constant at $1 \mathrm{~nm}$ and $5 \mathrm{~nm}$, respectively. Also, the drain voltage for transfer characteristics has been chosen to be $\mathrm{V}_{\mathrm{DD}}=1 \mathrm{~V}$. The simulation of transfer characteristics (drain current $\mathrm{I}_{\mathrm{d}}$-gate voltage $\mathrm{V}_{\mathrm{g}}$ ) has been conducted with different values of channel lengths $\mathrm{L}$, where $\mathrm{L}=25,50,100,200 \mathrm{~nm}$. 
Based on the obtained results that illustrated in Figure 3, the $\mathrm{I}_{\mathrm{ON}} / \mathrm{I}_{\mathrm{OFF}}$ ratio exponentially increases with the channel length less than $100 \mathrm{~nm}$, while, for channel length above $100 \mathrm{~nm}$ the $\mathrm{I}_{\mathrm{ON}} / \mathrm{I}_{\mathrm{OFF}}$ were almost constant. As shown in Figure 3, the maximum value of the $\mathrm{I}_{\mathrm{ON}} / \mathrm{I}_{\mathrm{OFF}}$ ratio is more than $3.2^{*} 10^{3}$ at $\mathrm{L} \geq 100 \mathrm{~nm}$. Figure 4 shows the relation of SS and DIBL characteristic with channel length, this figure explain that the SS improved and decreased as the channel length increased up to $50 \mathrm{~nm}$ and reached $72.6 \mathrm{mV} / \mathrm{dec}$, while, for $\mathrm{L} \geq 50 \mathrm{~nm}$, the values of SS were almost constant. For DIBL, the results in Figure 4 shows that the DIBL decreases with increasing channel length up to $100 \mathrm{~nm}$, then the values of DIBL were almost constant at $106 \mathrm{mV} / \mathrm{V}$.

Figure 5 shows the relation of length of gate with transconductance $\left(\mathrm{G}_{\mathrm{m}}\right)$ and threshold voltage $\left(\mathrm{V}_{\mathrm{T}}\right)$, both $V_{T}$ and $G m$ increased linearly with $L$ up to $L=50 \mathrm{~nm}$, then both $\left(G_{m}\right.$ and $\left.V_{T}\right)$ almost constant for $\mathrm{L} \geq 50 \mathrm{~nm}$. According these results the best and minimal $\mathrm{Lg}$ must be about $50 \mathrm{~nm}$ that has best DIBL, Gm and $\mathrm{V}_{\mathrm{T}}$ with acceptable $\mathrm{I}_{\mathrm{ON}} / \mathrm{I}_{\mathrm{OFF}}$.

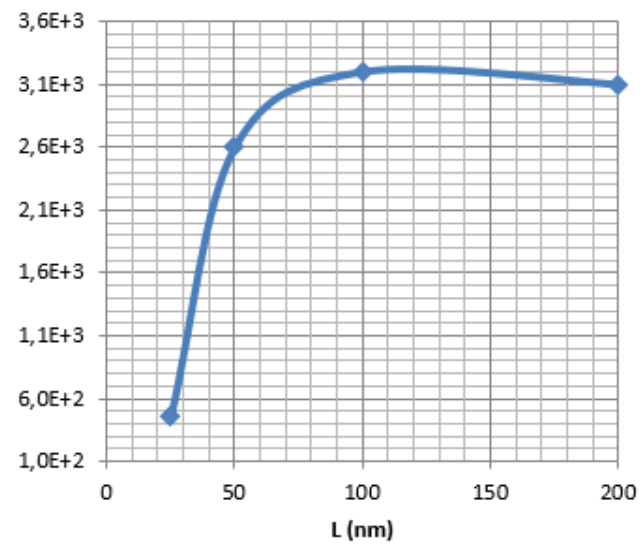

Figure 3. Characteristics of $\mathrm{I}_{\mathrm{ON}} / \mathrm{I}_{\mathrm{OFF}}$ ratio with $\mathrm{L}$

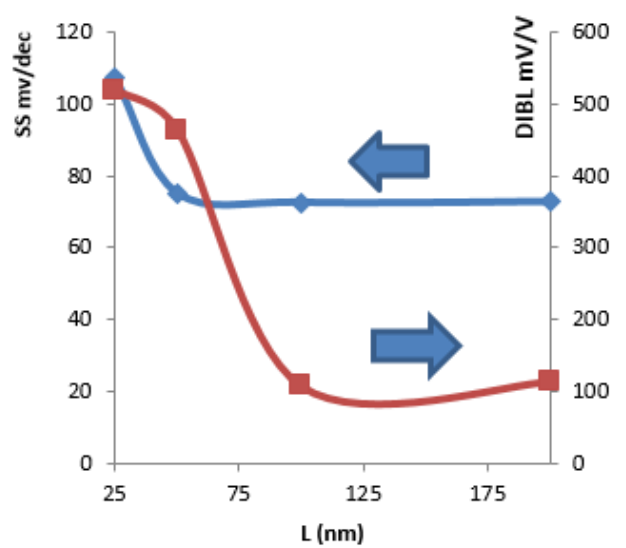

Figure 4. The characterestics of SS and DIBL with channel length

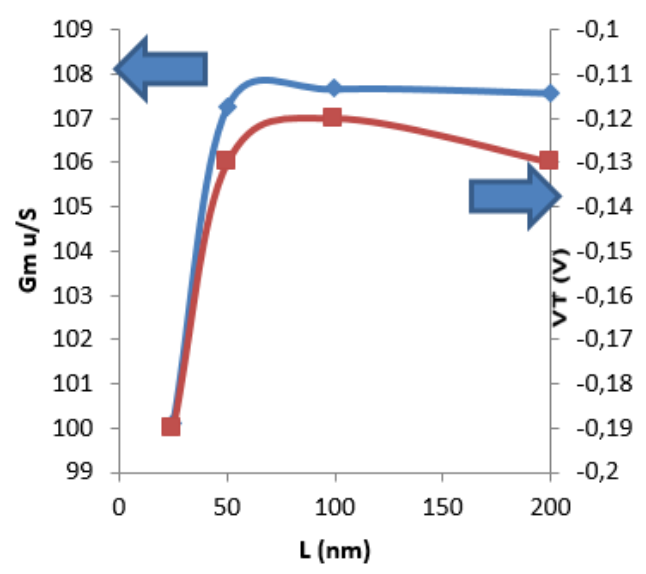

Figure 5. The length of gate effect on transconductance $\left(\mathrm{G}_{\mathrm{m}}\right)$ and threshold voltage $\left(\mathrm{V}_{\mathrm{T}}\right)$

\subsection{Downscaling channel radius}

The minimizing of channel radius $\mathrm{R}$ and its effect on the electrical characteristics of GAA TFET have been investigated in this section. The value of $\mathrm{R}$ was changed $(5,9,18$ and $25 \mathrm{~nm})$ while $\mathrm{L}=200 \mathrm{~nm}$ and $\mathrm{T}_{\mathrm{OX}}=15 \mathrm{~nm}$. Figure 6 shows the electrical characteristics of $\mathrm{I}_{\mathrm{ON}} / \mathrm{I}_{\mathrm{OFF}}$ ratio depending on the effect of changing channel radius $R$. The $\mathrm{I}_{\mathrm{ON}} / \mathrm{I}_{\mathrm{OFF}}$ ratio for both voltages $\left(\mathrm{V}_{\mathrm{D}}=1 \mathrm{~V}\right.$ and $\left.\mathrm{V}_{\mathrm{G}}=1.5 \mathrm{~V}\right)$. The $\mathrm{I}_{\mathrm{ON}} / \mathrm{I}_{\mathrm{OFF}}$ ratio is increasing proportional with increasing channel radius. It is possible to recognize that at $\mathrm{R}$ lower than $10 \mathrm{~nm}$ there are highly increasing in $\mathrm{I}_{\mathrm{ON}} / \mathrm{I}_{\mathrm{OFF}}$ ratios, while at $\mathrm{R}$ higher than $10 \mathrm{~nm}$ there are lower increasing in $\mathrm{I}_{\mathrm{ON}} / \mathrm{I}_{\mathrm{OFF}}$ ratios. So, if the channel dimeter minimize from $25 \mathrm{~nm}$ to $10 \mathrm{~nm}$, the $\mathrm{I}_{\mathrm{ON}} / \mathrm{I}_{\mathrm{OFF}}$ ratios with decreased 
from $3.9 * 10^{5}$ to $7 * 10^{4}$ respectively. While, the minimizing the channel radius from $10 \mathrm{~nm}$ to $5 \mathrm{~nm}$ will drop down the $\mathrm{I}_{\mathrm{ON}} / \mathrm{I}_{\mathrm{OFF}}$ ratios from $7 * 10^{4}$ to $3.2 * 10^{3}$ respectively.

Figure 7 depicts the variation of SS and DIBL values with variable channel radius. The SS highly improved and increased from 72.8 to $57.5 \mathrm{mV} / \mathrm{dec}$ when the radius changed from 5 to $10 \mathrm{~nm}$ respectively, the SS increased slightly to $50 \mathrm{mV} / \mathrm{dec}$ when the radius increased to $25 \mathrm{~nm}$. Figure 7 illustrate that the BIDL behavior look like same as SS, the DIBL improved and dropped highly also from 116 to $60 \mathrm{mV} / \mathrm{V}$ with radius from 5 to $10 \mathrm{~nm}$ respectively, and dropped slightly from 60 to $38 \mathrm{mV} / \mathrm{V}$ with the range of channel radius 10 to $25 \mathrm{~nm}$.

Furthermore, the impacts of varying channel radius on $V_{T}$ and $G_{m}$ are illustrated in Figure 8 . The threshold voltage is almost constant regardless channel width except at the $R=10 \mathrm{~nm}$, where $V_{T}$ scores the highest value of $0.13 \mathrm{~V}$. Finally, the $\mathrm{G}_{\mathrm{m}}$ increased as channel radius increased. GGA TFET achieved higher $G_{m}$ at $D=25 \mathrm{~nm}$, the $G_{m}$ characteristics increased with decreasing $R$ and achieved the lower value at $\mathrm{D}=5 \mathrm{~nm}$. According these results the minimal $\mathrm{R}$ with good electrical characteristics must be about $10 \mathrm{~nm}$ that has best DIBL, Gm and $\mathrm{V}_{\mathrm{T}}$ with acceptable $\mathrm{I}_{\mathrm{ON}} / \mathrm{I}_{\mathrm{OFF}}$.

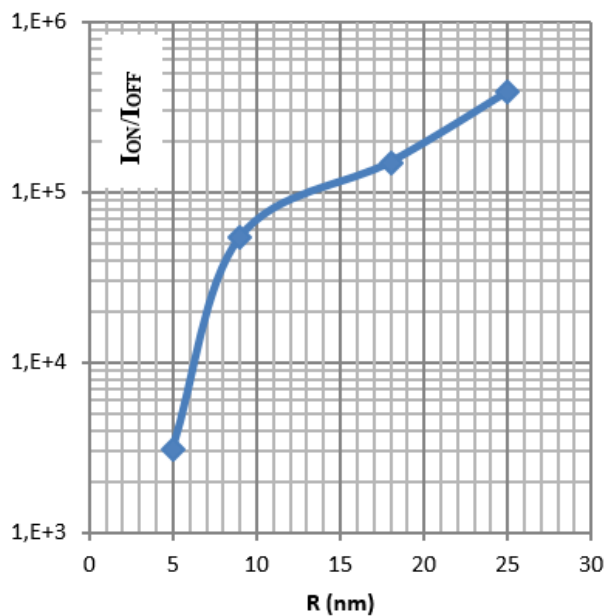

Figure 6. Characteristics of $\mathrm{I}_{\mathrm{ON}} / \mathrm{I}_{\mathrm{OFF}}$ ratio with $\mathrm{R}$

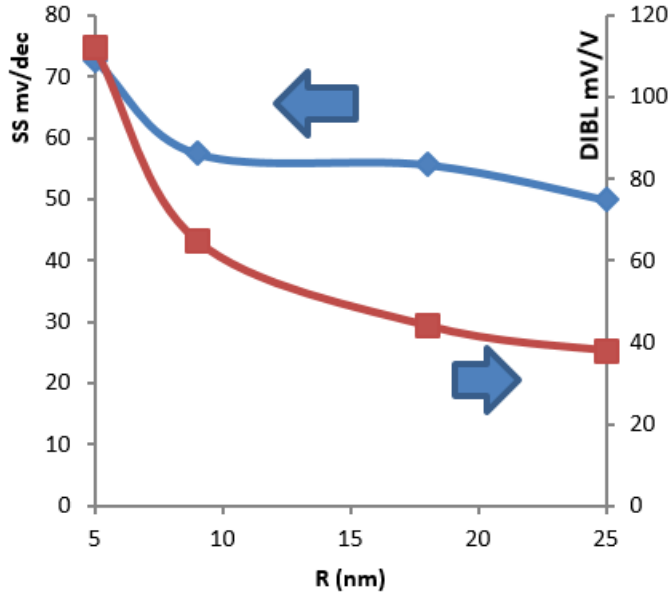

Figure 7. The variation of SS and DIBL with R

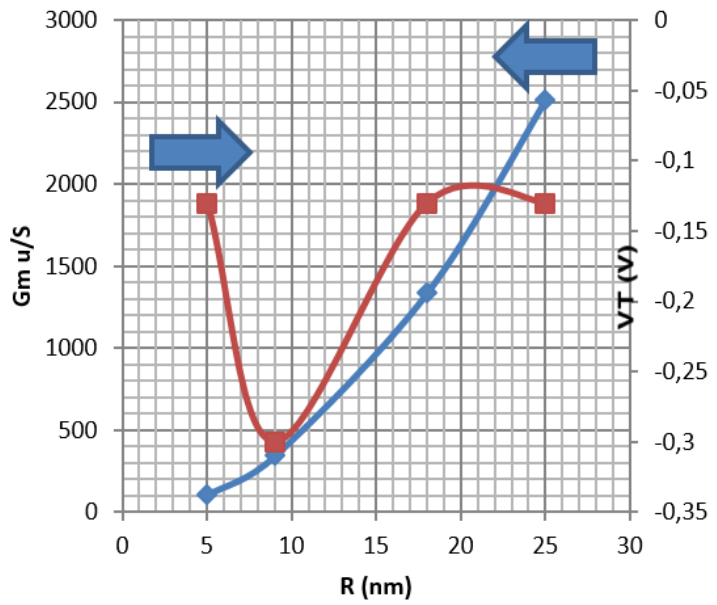

Figure 8. Characteristics of $\mathrm{V}_{\mathrm{T}}$ and $\mathrm{G}_{\mathrm{m}}$ with $\mathrm{R}$

\subsection{Downscaling channel oxide thickness}

Figures 9 to 11 show the channel oxide thickness variation in relation to the electrical characteristics of GAA TFET. For this simulation step, $\mathrm{T}_{\mathrm{OX}}$ has been varied $(1,2,3$ and $4 \mathrm{~nm})$, the channel length and channel radius has been kept constant at $200 \mathrm{~nm}$ and 5nm respectively. Figure 9 illustrates the relation 
between the $\mathrm{I}_{\mathrm{ON}} / \mathrm{I}_{\mathrm{OFF}}$ ratio with the channel oxide thickness. The minimum $\mathrm{I}_{\mathrm{ON}} / \mathrm{I}_{\mathrm{OFF}}$ ratio $\left(3.1^{*} 10^{3}\right)$ with $\mathrm{V}_{\mathrm{DD}}=1 \mathrm{~V}$ was obtained at minimum $\mathrm{T}_{\mathrm{OX}}=1 \mathrm{~nm}$ and then increased to $2.5^{*} 10^{13}$ at $\mathrm{T}_{\mathrm{OX}}=4 \mathrm{~nm}$. From the results shown in Figure 10, it is clear that for a lower channel oxide thickness, $\mathrm{T}_{\mathrm{OX}}=1 \mathrm{~nm}$ the TFET has shown worse SS characteristics with the best SS value of $72.8 \mathrm{mV} / \mathrm{dec}$ compared to other $\mathrm{T}_{\text {ox }}$ values. The $\mathrm{SS}$ improved with increasing $\mathrm{T}_{\mathrm{OX}}$ and the best value $(21.4 \mathrm{mV} / \mathrm{V})$ was at $\mathrm{T}_{\mathrm{OX}}=3 \mathrm{~nm}$. Figure 10 also displays channel oxide thickness versus DIBL characteristics of TFET. DIBL increased linearly with increasing $\mathrm{T}_{\mathrm{OX}}$, the best value at $T_{O X}=1 \mathrm{~nm}$. Figure 11 represents the relation of both $V_{T}$ and $G_{m}, G_{m}$ has a peak value at $2 n m$ while $V_{T}$ increased with increasing Tox and its value almost constant after $T_{O X}=1 \mathrm{~nm}$. According these results the minimal $\mathrm{T}_{\mathrm{OX}}$ with good electrical characteristics must be $2 \mathrm{~nm}$ that has best DIBL, Gm and $\mathrm{V}_{\mathrm{T}}$ with acceptable $\mathrm{I}_{\mathrm{ON}} / \mathrm{I}_{\mathrm{OFF}}$.

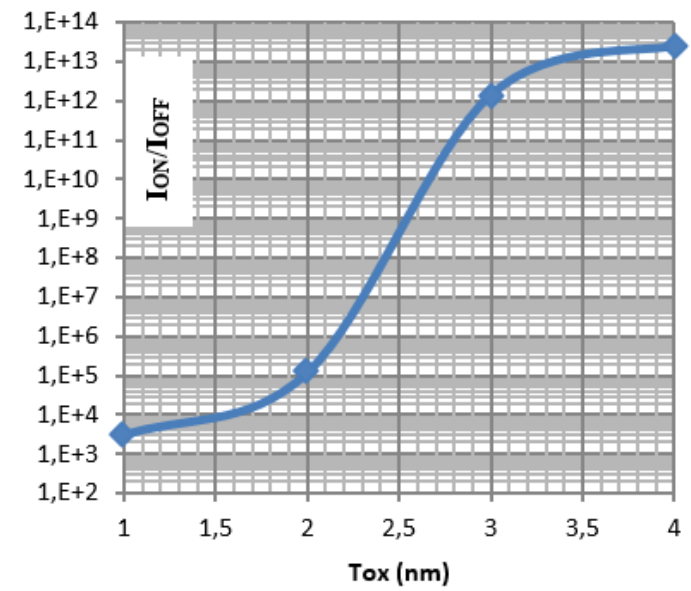

Figure 9. Characteristics of $\mathrm{I}_{\mathrm{ON}} / \mathrm{I}_{\mathrm{OFF}}$ ratio with $\mathrm{T}_{\mathrm{OX}}$

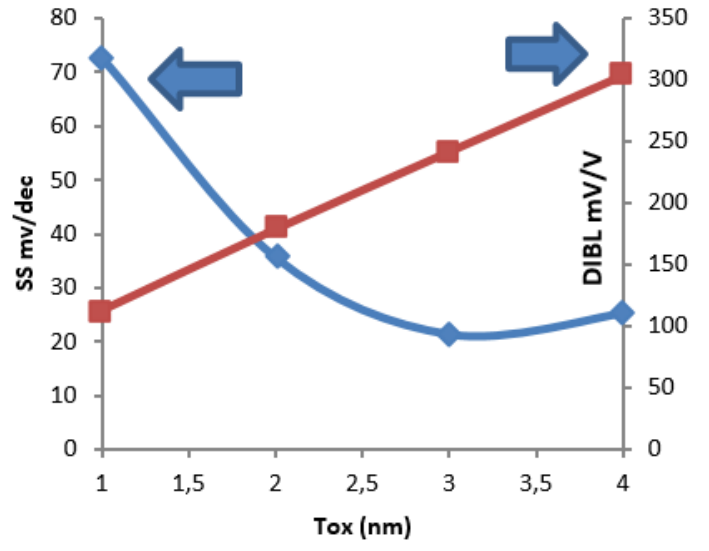

Figure 10. The characterestics of SS and DIBL with Tox

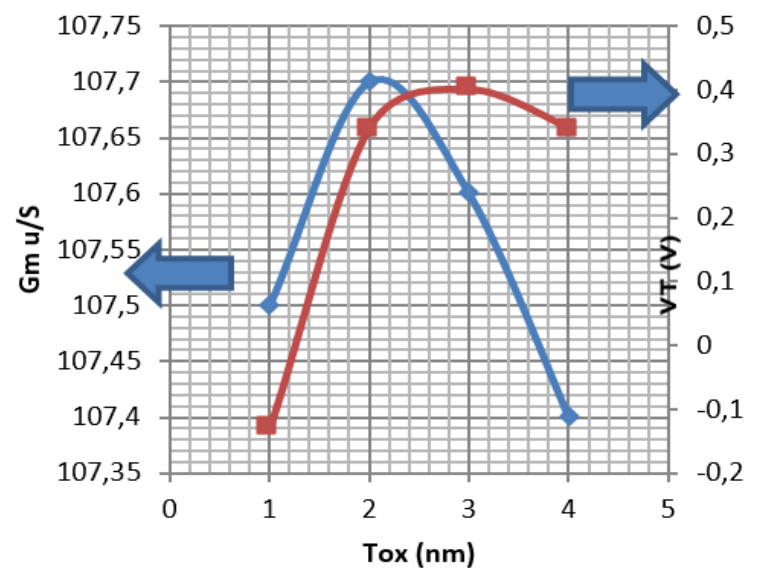

Figure 11. Characteristics of $\mathrm{V}_{\mathrm{T}}$ and $\mathrm{G}_{\mathrm{m}}$ with $\mathrm{T}_{\mathrm{OX}}$

\section{CONCLUSION}

The downscaling effect on the electrical characteristics of GAA Si-NW TFET has been investigated, TCAD simulation tool has been used to create the output characteristics of TFET and the critical parameters related to the electrical characteristics transistor. Downscaling of length of channel (L), radios of nanowire of channel (R), and oxide thickness $\left(\mathrm{T}_{\mathrm{OX}}\right)$ and its effect on the $\mathrm{I}_{\mathrm{ON}} / \mathrm{I}_{\mathrm{OFF}}$ ratio, sub-threshuld swing (SS), drain indused barrier lowering (DIBL), treshuld voltage $\left(\mathrm{V}_{\mathrm{T}}\right)$, and transconductance $\left(\mathrm{G}_{\mathrm{m}}\right)$ of channel have been studied. The results shows that the minimal channel length with good electrical characteristics was at 50nm, the minimal channel redius with good electrical characteristics was at $10 \mathrm{~nm}$, and finally, the minimal channel oxide thickness with good electrical characteristics was at range 2 to $3 \mathrm{~nm}$. 


\section{ACKNOWLEDGEMENTS}

The authors would like to thank Ishik International university (TIU), University of Mosul, and University Malaysia Pahang (UMP) for their support, This work was supported by the RDU Grant (No: RDU1803150) of the Universiti Malaysia Pahang, Malaysia.

\section{REFERENCES}

[1] M. Neisser and S. Wurm, "ITRS lithography roadmap: 2015 challenges," Advanced Optical Technologies, vol. 4, no. 4, pp. 235-240, 2015.

[2] S. Bangsaruntip, et al., "High performance and highly uniform gate-all-around silicon nanowire MOSFETs with wire size dependent scaling," IEEE Int. Electron Devices Meeting, Baltimore, pp. 1-4, 2009.

[3] Y. Hashim O. Sidek, "Dimensional Effect on DIBL in Silicon Nanowire Transistors," Advanced Materials Research, vol. 626, pp. 190-194, 2013

[4] H. T. Al Ariqi, W. A. Jabbar, Y. Hashim, H. B. Manap, "Characterization of silicon nanowire transistor," TELKOMNIKA Telecommunication, Computing, Electronics and Control, vol. 17, no. 6, pp. 2860-2866, 2019.

[5] Y. Hashim, "Optimization of Resistance Load in 4T-Static Random-Access Memory Cell Based on Silicon Nanowire Transistor," Journal of Nanoscience and Nanotechnology, vol. 18, no. 2, pp. 1199-1201, 2018.

[6] V. M. Srivastava, K. S. Yadav, and G. Singh, "Design and performance analysis of cylindrical surrounding doublegate MOSFET for RF switch,” Microelectronics Journal, vol. 42, no.10, pp. 1124-1135, 2011.

[7] A. H. Bayani, D. Dideban, J. Voves, and N. Moezi, "Investigation of sub-10nm cylindrical surrounding gate germanium nanowire field effect transistor with different cross-section areas," Superlattices and Microstructures, vol. 105, no. 1, pp. 110-116, 2017.

[8] V. M. Srivastava, "Small signal model of cylindrical surrounding double-gate MOSFET and its parameters," Int. Conf. on Trends in Automation, Communications and Computing Technology, pp. 1-5, 2015.

[9] S. K. Dargar and V. M. Srivastava, "Analysis of short channel effects in multiple-gate (n, 0) carbon nanotube FETs," Journal of Engineering Science and Technology, vol. 14, no. 6, pp. 3282-3293, 2019.

[10] N. Singh, et al., "High-performance fully depleted silicon nanowire (diameter/spl les/5 nm) gate-all-around CMOS devices," IEEE Electron Device Letters, vol. 27, no. 5, pp. 383-386, 2006.

[11] S. K. Dargar and V. M. Srivastava, "Performance analysis of $10 \mathrm{~nm}$ FinFET with scaled fin-dimension and oxide thickness," International Conference on Automation, Computational and Technology Management, 2019.

[12] A. K. Bansal, et al., "3-D LER and RDF Matching Performance of Nanowire FETs in Inversion, Accumulation, and Junctionless Modes," IEEE Transactions on Electron Devices, vol. 65, no. 3, pp. 1246-1252, 2018.

[13] M. I. Dewan, M. T. B. Kashem, and S. Subrina, "Characteristic analysis of triple material tri-gate junctionless tunnel field effect transistor," 9th Int. Conf. on Electrical and Computer Engineering (ICECE), pp. 333-336, 2016.

[14] A. Seabaugh, "The Tunneling Transistor," IEEE Spectrum, vol. 50, no. 10, pp. 35-62, 2013.

[15] W. Y. Choi, B. G. Park, J. D. Lee, and T. J. K. Liu, "Tunneling field-effect transistors (TFETs) with Subthreshold Swing (SS) less than $60 \mathrm{mV} / \mathrm{dec}$," IEEE Electron Device Letters, vol. 28, no. 8, pp. 743-745, 2007.

[16] Ahmed Mahmood, Waheb A Jabbar, Yasir Hashim, Hadi Bin Manap, "Effects of downscaling channel dimensions on electrical characteristics of InAs-FinFET transistor," International Journal of Electrical \& Computer Engineering (IJECE), vol. 9, no. 4, pp. 2902-2909, 2019.

[17] Y Hashim, "Temperature effect on ON/OFF current ratio of FinFET transistor," IEEE Regional Symposium on Micro and Nanoelectronics (RSM), pp. 231-234, 2017.

[18] Y. Guan, Z. Li, W. Zhang, and Y. Zhang, "An accurate analytical current model of double-gate heterojunction tunneling FET," IEEE Trans. on Electron Devices, vol. 64, no. 3, pp. 938-944, 2017

[19] A. C. Seabaugh and Q. Zhang, "Low-Voltage Tunnel Transistors for Beyond CMOS Logic," Proceedings of the IEEE, vol. 98, no. 12, pp. 2095-2110, 2010.

[20] B. Jena, S. Dash and G. P. Mishra, "Improved Switching Speed of a CMOS Inverter Using Work-Function Modulation Engineering," IEEE Trans. on Electron Devices, vol. 65, no. 6, pp. 2422-2429, 2018.

[21] A. Kumar, S. Bhushan, and P. K. Tiwari, "A threshold voltage model of silicon-nanotube-based ultrathin double gate-all-around (DGAA) MOSFETs incorporating quantum confinement effects," IEEE Trans. on Nanotechnology, vol. 16, no. 5, pp. 868-875, 2017.

[22] J. Dura, et al., "Analytical model of drain current in nanowire MOSFETs including quantum confinement, band structure effects and quasi-ballistic transport: device to circuit performances analysis," Int. Conf. on Simulation of Semiconductor Processes and Devices (ICSSPD), pp. 43-46, 2011.

[23] H. R. T. Khaveh, S. Mohammadi, "Potential and drain current modeling of gate-all-around tunnel FETs considering the junctions depletion regions and the channel mobile charge carriers," IEEE Trans. on Electron Devices, vol. 63, no. 12 , pp. 5021-5029, 2016.

[24] S. Glass et al., "A Novel Gate-Normal Tunneling Field-Effect Transistor With Dual-Metal Gate," IEEE Journal of the Electron Devices Society, vol. 6, pp. 1070-1076, 2018.

[25] AC Seabaugh, Q Zhang., "Low-Voltage Tunnel Transistors for Beyond CMOS Logic," Proceedings of the IEEE, vol. 98, no. 12, pp. 2095-2110, 2010.

[26] S. Kang, et al., "Interlayer tunnel fieldeffect transistor (ITFET): Physics, fabrication and applications," Journal of Physics D: Applied Physics, vol. 50, no. 38, 2017. 
[27] M. Khaouani, and A. Guen-Bouazza, "Impact of multiple channels on the characteristics of rectangular GAA MOSFET," International Journal of Electrical and Computer Engineering (IJECE), vol. 7, no. 4, pp. 1899-1905, 2017.

[28] E. O. Kane, “Theory of tunneling," Journal of Applied Physics, vol. 32, no. 1, pp. 83-91, 1961

\section{BIOGRAPHIES OF AUTHORS}

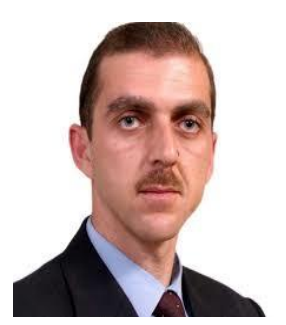

Firas N. Abdul-kadir received the B.Sc. in Medical Instruments Engineering from Mosul Technical College and Master of Engineering in Electronics and Communications Engineering from the University of Mosul, Mosul, Iraq, in 1998 and 2013 respectively. He is currently an Assistant Lecturer in the Department of Electrical Engineering, College of Engineering, Mosul University, Mosul, Iraq. His research interests include Microelectronics and Nanoelectronic, MOSFET nono-structure and carbon-nano tube (CNT). Email: firas_nadheer@uomosul.edu.iq

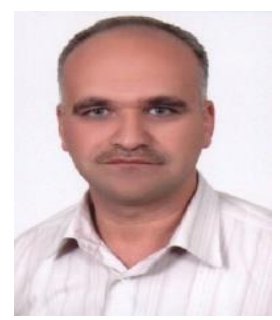

Yasir Hashim (SMIEEE) received the B.Sc. and Master of Engineering in Electronics and Communications Engineering from the University of Mosul, Mosul, Iraq, in 1991 and 1995 respectively. He completed the Ph.D. in Electronics Engineering-Micro and Nanoelectronics from Universiti Science Malaysia (USM), Penang, Malaysia, in 2013. He is currently a Senior Lecturer in the Department of Computer Engineering, Faculty of Engineering, Ishik University, Erbil-Kurdistan, Iraq. His research interests include Microelectronics and Nanoelectronic: Nanowire transistors, FinFET transistor, Multistage Logic Nano-inverters.

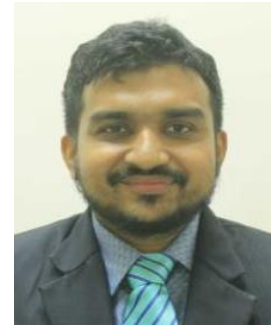

Mohammed Nazmus Shakib received his B.Sc. degree in Electronics Engineering from Multimedia University, Malaysia, the M.Sc. degree from National University of Malaysia, Malaysia and the Ph.D. from the University of Malaya, Malaysia. He is currently attached to the Faculty of Electrical \& Electronics Engineering Technology, University Malaysia Pahang, Malaysia. He has published many international conferences and journals. He is also a Reviewer of a few journals such as IET, PIER, JEMWA, IEEE Access, Elsevier, etc. His research interests mainly include electronics, sensors, RF, measurement antennas, patch antennas, wearable devices, implantable devices, wireless communication and UWB technology.

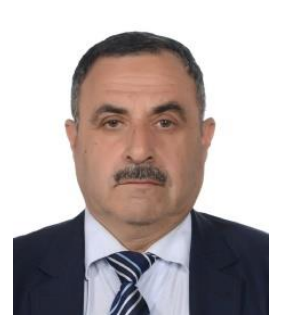

Faris Hassan Aldabbagh received the MSc degree in Electronic and communication from the University of Mosul, Mosul, Iraq, in 1995 and received PhD degree in 2013 in Solid State Electronics from University of Mosul, Mosul, Iraq. His research interests include Microelectronics and Nanoelectronic. 